\title{
ARTICLE OPEN \\ Steel corrosion inhibition by calcium nitrate in halide-enriched completion fluid environments
}

\author{
Shiqi Dong ${ }^{1,2}$, Erika Callagon La Plante ${ }^{1}$, Xin Chen ${ }^{1}$, Mehrdad Torabzadegan ${ }^{3}$, Magdalena Balonis ${ }^{2}$, Mathieu Bauchy ${ }^{4}$ and \\ Gaurav Sant ${ }^{1,2,5}$
}

Calcium nitrate $\left(\mathrm{Ca}\left(\mathrm{NO}_{3}\right)_{2}\right)$ has been suggested to inhibit steel corrosion. However, the effectiveness of corrosion inhibition offered by calcium nitrate in highly halide-enriched environments, for example, completion fluids, is not well known. To better understand this, the inhibition of corrosion of API P110 steel by $\mathrm{Ca}\left(\mathrm{NO}_{3}\right)_{2}$ was studied using vertical scanning interferometry in solutions consisting of 10 mass \% calcium chloride $\left(\mathrm{CaCl}_{2}\right)$ or 10 mass \% calcium bromide $\left(\mathrm{CaBr}_{2}\right)$, for example, to simulate the contact of completion fluids with the steel sheath in downhole (oil and gas) applications. The evolution of the surface topography resulting from the initiation and growth of corrosion pits, and general corrosion was examined from the nano-scale to micron-scale using vertical scanning interferometry. Special focus was paid to quantify surface evolution in the presence of $\mathrm{Ca}\left(\mathrm{NO}_{3}\right)_{2}$. The results indicate that, at low concentrations ( $\approx 1$ mass \%), $\mathrm{Ca}\left(\mathrm{NO}_{3}\right)_{2}$ successfully inhibited steel corrosion in the presence of both $\mathrm{CaCl} 2$ and $\mathrm{CaBr}_{2}$. Statistical analysis of surface topography data reveals that such inhibition results from suppression of corrosion at fast corroding pitting sites. However, at higher concentrations, calcium nitrate's effectiveness as a corrosion inhibitor is far less substantial. These results provide a means to rationalize surface topography evolution against the electrochemical origin of corrosion inhibition by $\mathrm{NO}_{3}{ }^{-}$species, and provide guidance regarding the kinetics, and susceptibility to degradation of the steel sheath during exposure to halide-enriched completion fluids.

npj Materials Degradation (2018)2:32; doi:10.1038/s41529-018-0051-4

\section{INTRODUCTION}

High-density brines have long been used during drilling, completion, and workover operations during oil and gas production. ${ }^{1}$ Concentrated aqueous solutions of halide salts of alkali and alkaline earth metals, which provide high fluid density while minimizing cost, are commonly used in these applications. ${ }^{1}$ However, such high concentrations of halides, particularly chloride $\left(\mathrm{Cl}^{-}\right)$and bromide $\left(\mathrm{Br}^{-}\right)$, are likely to result in significant corrosion of the steel pipe (sheath) that conveys fluid hydrocarbons to the surface. $^{2-4}$ Halides induce steel corrosion by a variety of processes including: break down of the airborne oxidation film, accelerating pit formation, and facilitating pit growth. ${ }^{5-7}$ Chloride ions are considered to be more aggressive than $\mathrm{Br}^{-}$due to their higher electron affinity and stronger adsorption on the oxidation film surface. $^{8}$

Inhibitors such as calcium nitrite $\left(\mathrm{Ca}\left(\mathrm{NO}_{2}\right)_{2}\right)$ and calcium nitrate $\left(\mathrm{Ca}\left(\mathrm{NO}_{3}\right)_{2}\right)$ are known to retard the corrosion of reinforcing steel. ${ }^{9-}$

11 While $\mathrm{Ca}\left(\mathrm{NO}_{3}\right)_{2}$ is cheap and abundant, its ability to inhibit corrosion in highly concentrated halide environments is not known. Nevertheless, it has been suggested that nitrate inhibits corrosion by facilitating the formation of ferric hydroxide $\left(\mathrm{Fe}(\mathrm{OH})_{3}\right)$ in the anodic corrosion region, decreasing the extent of iron migration as aqueous ferrous/ferric chlorocomplexes, and thereby reducing iron dissolution. ${ }^{10,12}$ While corrosion inhibition by $\mathrm{Ca}$ $\left(\mathrm{NO}_{3}\right)_{2}$ has been studied using electrochemical methods ${ }^{13,14}$ direct observations of corroding surfaces from the nano-scale to micron-scale, which can be rationalized against electrochemical studies, have remained broadly unavailable.

Vertical scanning interferometry (VSI) can be used to study the kinetics of reactions at solid-liquid interfaces, including mineral dissolution, precipitation, and metallic corrosion at unparalleled resolution. ${ }^{15-17}$ The high lateral and vertical resolution ${ }^{18}$ of VSI makes it ideally suited to monitor small changes in the topography of steel surfaces, due to processes such as the dissolution of steel, ${ }^{19}$ precipitation of corrosion products, ${ }^{20}$ and the growth of the passive films ${ }^{21}$, from the nano-scale to micronscale. This capability offers significant advantages over electrochemical methods which, most often, can only measure bulk behavior. ${ }^{13,14}$ Furthermore, the capability to probe spatially localized corrosion over large sample areas $\left(10 \mathrm{~s}\right.$ of $\left.\mathrm{mm}^{2}\right)$ presents advantages over scanning probe techniques, which are most often restricted to examining small, very localized surface areas. $^{22,23}$

Herein, the retarding effect of $\mathrm{Ca}\left(\mathrm{NO}_{3}\right)_{2}$ on the corrosion of American Petroleum Institute (API) P110 steel is examined in the presence of brines composed using calcium chloride $\left(\mathrm{CaCl}_{2}\right)$ or calcium bromide $\left(\mathrm{CaBr}_{2}\right)^{24,25} \mathrm{VSI}$ is used to quantitatively and statistically analyze three-dimensional (3D) surface topographies, and their evolution, in time to reveal the mechanisms by which $\mathrm{Ca}$ $\left(\mathrm{NO}_{3}\right)_{2}$ alters and suppresses halide-induced corrosion. The outcomes support the use of $\mathrm{Ca}\left(\mathrm{NO}_{3}\right)_{2}$-based brines in completion

\footnotetext{
'Laboratory for the Chemistry of Construction Materials LC ${ }^{2}$, Department of Civil and Environmental Engineering, University of California, Los Angeles, CA, USA; ${ }^{2}$ Department of Materials Science and Engineering, University of California, Los Angeles, CA, USA; ${ }^{3}$ Yara International ASA, Yara Technology Center, Porsgrunn, Norway; ${ }^{4}$ Laboratory for the Physics of Amorphous and Inorganic Solids (PARISlab), Department of Civil and Environmental Engineering, University of California, Los Angeles, CA, USA and ${ }^{5}$ California Nanosystems Institute (CNSI), University of California, Los Angeles, CA, USA

Correspondence: Gaurav Sant (gsant@ucla.edu)
}

Received: 21 May 2018 Revised: 20 August 2018 Accepted: 24 August 2018

Published online: 13 September 2018 
and workover fluid environments and provide insights into its behavior as a corrosion inhibitor.

\section{RESULTS AND DISCUSSION}

Corrosion inhibition by calcium nitrate in the presence of halidecontaining brines

Figure 1 shows representative height change maps of the steel surfaces following immersion in brines consisting of 10 mass $\%$ $\mathrm{CaCl}_{2}$ and 10 mass $\% \mathrm{CaBr}_{2}$ solutions for $0,1,3$, and 7 days. Expectedly, characteristic general corrosion features are observed following exposure to halide brines. ${ }^{28,29}$ This includes processes encompassing the initiation, propagation, and accumulation of corrosion pits. ${ }^{30}$ Quantitative evolutions of the average surface height change of API P110 steel over time as a function of $\mathrm{Ca}$ $\left(\mathrm{NO}_{3}\right)_{2}$ dosage in the presence of $10 \% \mathrm{CaCl}_{2}$ and $10 \% \mathrm{CaBr}_{2}$ brines are shown in Fig. 2a, b. A linear function fitted to the data set reveals the net reaction rate, that is, including steel dissolution and corrosion. The uncertainty in rates is estimated to be around $15 \%$ based on replicate experiments. The relative corrosion rates in the presence of various dosages of $\mathrm{Ca}\left(\mathrm{NO}_{3}\right)_{2}, \mathrm{RCR}_{\mathrm{CN}}$, were calculated as:

$$
\mathrm{RCR}_{\mathrm{CN}}=\frac{\mathrm{CR}_{\mathrm{CN}}}{\mathrm{CR}_{0}},
$$

where $C R_{C N}$ and $C R_{0}$ refer to corrosion rates in the presence and absence of $\mathrm{Ca}\left(\mathrm{NO}_{3}\right)_{2}$, respectively (see Fig. 2c, d).

The average height change and corrosion rate data reveals that steel corrosion is enhanced and accelerated in $\mathrm{CaCl}_{2}$ as compared to $\mathrm{CaBr}_{2}$. This is also evident from the VSI images in Fig. 1, which highlight the smaller dimensions and shallower depths of pits in the latter case. This behavior is expected to be on the account of the somewhat lower $\mathrm{pH}$ of the chloride solutions than the bromide solutions (see Table 1), and the higher electronic density, and smaller anion size of $\mathrm{Cl}^{-}$ions as compared to $\mathrm{Br}^{-}$ions, which facilitates their penetration into and subsequent disruption of the air-formed oxide film that is present on steel surfaces. ${ }^{8,31}$
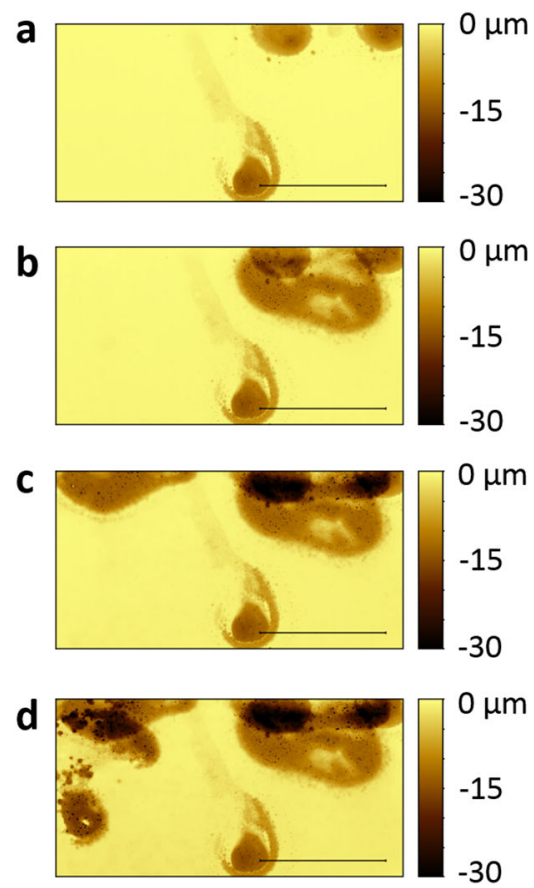

Fig. 1 Representative height change maps of API P110 steel surfaces obtained using vertical scanning interferometry after immersion in a 10 mass $\% \mathrm{CaCl}_{2}$ brine for: a 1 day, $\mathbf{b} 3$ days, $\mathbf{c} 5$ days, and $\mathbf{d} 7$ days. The height change maps following periods of exposure to a 10 mass $\%$ CaBr ${ }_{2}$ brine are shown in $\mathbf{e}$ to $\mathbf{h}$ for the same reaction times, respectively. The height change is calculated with respect to the initial, pristine (unreacted) steel surface. The scale bars represent a length of $2 \mathrm{~mm}$ concentrations of $\mathrm{Ca}\left(\mathrm{NO}_{3}\right)_{2}$ are generally more effective at inhibiting corrosion than higher concentrations. Also, at low nitrate concentrations ( $\leq 1$ mass $\%$ ), the extent of inhibition enhances with increasing $\mathrm{Ca}\left(\mathrm{NO}_{3}\right)_{2}$ concentration. Indeed, a minimum in the corrosion rate is observed at a $\mathrm{Ca}\left(\mathrm{NO}_{3}\right)_{2}$ concentration of 1 mass \% following exposure to both $\mathrm{CaCl}_{2}$ and $\mathrm{CaBr}_{2}$ brines. This result is consistent with previous findings which indicate that low(er) concentrations of $\mathrm{Ca}\left(\mathrm{NO}_{3}\right)_{2}$ are suited for ensuring inhibition. ${ }^{10}$ Increasing the dosage of $\mathrm{Ca}\left(\mathrm{NO}_{3}\right)_{2}$ to 10 mass \% decreased the effectiveness for inhibition in both halidecontaining solutions. This observation is further discussed below.

The mechanism of corrosion inhibition by $\mathrm{Ca}\left(\mathrm{NO}_{3}\right)_{2}$ is revealed by statistical analysis of surface height evolutions and microstructural observations

Statistical analysis of corroding surface topographies was carried out for steel samples exposed to $\mathrm{CaCl}_{2}$ brines-both in the absence of and in the presence of $\mathrm{Ca}\left(\mathrm{NO}_{3}\right)_{2}$. The representative frequency distributions of surface height change of steel surfaces corresponding to the height change maps in Fig. 1a-d are shown in Fig. 3a. The frequency values in the distribution plots are normalized to the total number of pixels-thereby indicative of the percentage of the total surface area that is occupied by a given corrosion feature.

To offer quantitative analysis and the significance of the (height change) frequency distributions, first, the data were fitted using a two-term Gaussian function of the form:

$f(x)=a_{1} \cdot \exp \left(-\left(\frac{x-b_{1}}{c_{1}}\right)^{2}\right)+a_{2} \cdot \exp \left(-\left(\frac{x-b_{2}}{c_{2}}\right)^{2}\right)$

where $x, a, b$, and $c$ denote height change, a scaling factor for frequency, mean height change, and the spread in height change, respectively. The subscripts 1 and 2 denote the main peak and secondary peak, respectively. The fitting exercise revealed main peaks, centered at $-0.53,-0.88,-1.52$, and $-1.86 \mu \mathrm{m}$ for reaction
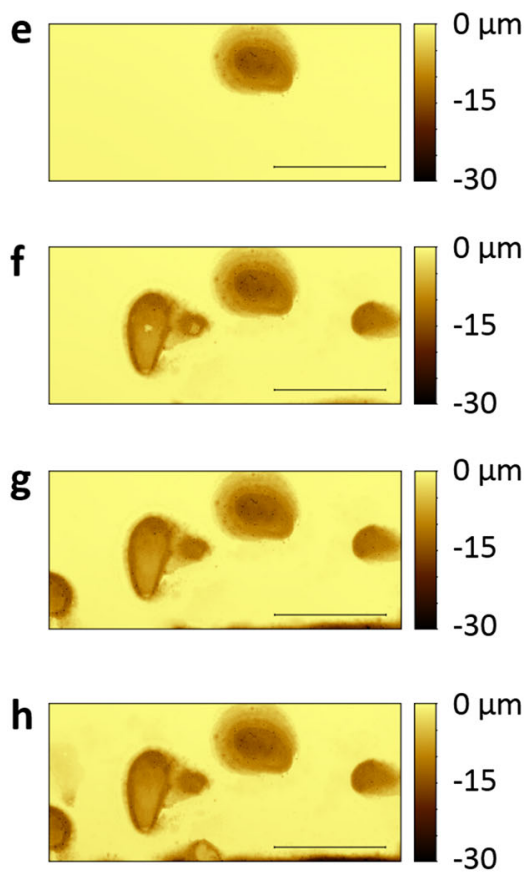


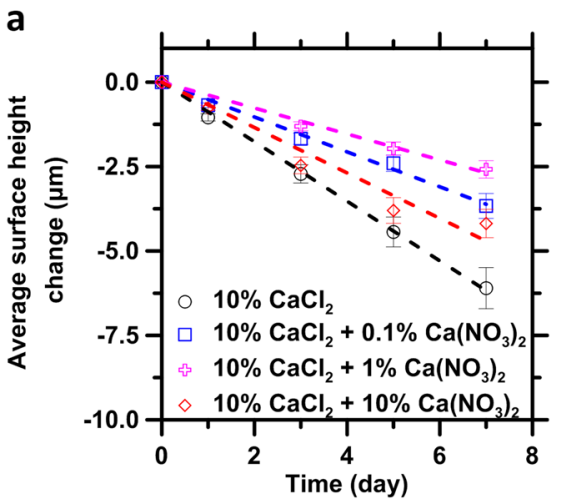

C

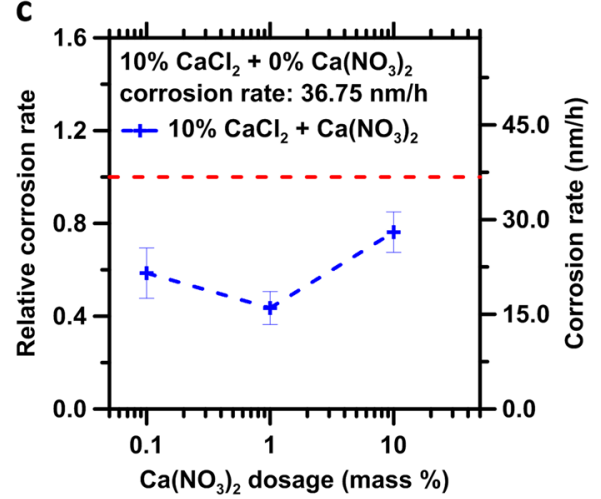

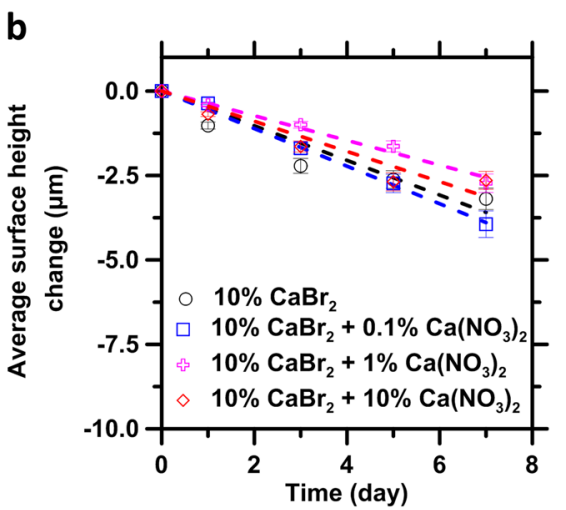

d

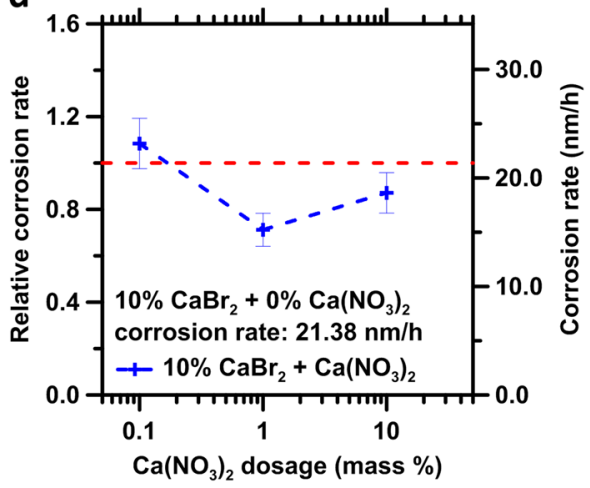

Fig. 2 The $\mathbf{a}, \mathbf{b}$ average surface height change and $\mathbf{c}, \mathbf{d}$ relative and absolute corrosion rates of API P110 steel surfaces over time in a, $\mathbf{c} 10$ mass $\% \mathrm{CaCl}_{2}$, and $\mathbf{b}$, $\mathbf{d} 10$ mass $\% \mathrm{CaBr}_{2}$ brines containing $0,0.1,1$, and 10 mass $\% \mathrm{Ca}\left(\mathrm{NO}_{3}\right)_{2}$. The dashed lines in $\mathbf{a}$, $\mathbf{b}$ indicate the best-fit lines for each data set, whose slope reveals the net corrosion (reaction) rate shown by the secondary $y$-axis in $\mathbf{c}$, $\mathbf{d}$. The ratio of corrosion rates in the presence and absence of $\mathrm{Ca}\left(\mathrm{NO}_{3}\right)_{2}$, that is, relative corrosion rates, are also shown in $\mathbf{c}$, $\mathbf{d}$ on the main $y$-axis. The dashed lines in $\mathbf{c}$, $\mathbf{d}$ indicate the corrosion rates and relative corrosion rates when $\mathrm{Ca}\left(\mathrm{NO}_{3}\right)_{2}$ is absent. The error bars represent the standard error of the mean

Table 1. The $\mathrm{pH}$ of the solutions used in the corrosion

\begin{tabular}{lllll}
\hline & $0 \% \mathrm{Ca}\left(\mathrm{NO}_{3}\right)_{2}$ & $\begin{array}{l}0.1 \% \mathrm{Ca} \\
\left(\mathrm{NO}_{3}\right)_{2}\end{array}$ & $1 \% \mathrm{Ca}\left(\mathrm{NO}_{3}\right)_{2}$ & $\begin{array}{l}10 \% \mathrm{Ca} \\
\left(\mathrm{NO}_{3}\right)_{2}\end{array}$ \\
\hline $10 \% \mathrm{CaCl}_{2}$ & 6.09 & 6.16 & 6.21 & 6.25 \\
$10 \% \mathrm{CaBr}_{2}$ & 8.91 & 8.98 & 8.90 & 8.87 \\
\hline
\end{tabular}

times of 1, 3, 5, and 7 days, respectively. These peak values are smaller than the average surface height change, that is, -1.04 , $-2.72,-4.44$, and $-6.10 \mu \mathrm{m}$ (Fig. 2a) at the corresponding reaction times. Indeed, the main peaks represent slowly corroding areas (lighter brown shade) shown in Fig. 1a-d. The areas identified by the main peak encompass $40-60 \%$ of all pixelsindicating that a majority of the steel surface is only slightly affected by corrosion. A broader distribution to the left (i.e., more negative values of height change) of the main peak is observed that is labeled by dashed lines in Fig. 3a. The secondary peaks correspond to height changes in the range of -8 to $-20 \mu \mathrm{m}$, consistent with localized regions undergoing much higher surface retreat (darker brown in color scale) as compared to the bulk surface seen in Fig. 1a-d. As time elapsed, the positions of the secondary peaks shifted by around $5 \mu \mathrm{m}$ to more negative values as denoted by the horizontal orange arrow, suggesting that localized sites-for example, pits-serve as fast reaction zones that recess at a rate that is much higher than the bulk alloy surface. In addition, it should be noted that the normalized frequency of pixels increased (as marked by vertical green arrows; see Fig. 3a) implying that the extent of the surface affected by corrosion increased due to growth and coalescence of existing pitted areas, and the formation of new pits. As such, section loss due to corrosion results from both: (1) general recession of the steel surface to a small extent (by $<2 \mu \mathrm{m}$ after 7 days) and (2) fast localized corrosion that manifests by the deepening and lateral growth of pitting sites.

Figure 3b-d illustrates the effects of $\mathrm{Ca}\left(\mathrm{NO}_{3}\right)_{2}$ dosage on corrosion rates for API P110 steel exposed to 10 mass $\% \mathrm{CaCl}_{2}$ brine. Foremost, at low dosages of $\mathrm{Ca}\left(\mathrm{NO}_{3}\right)_{2}$ (i.e., 0.1 mass $\%$ and 1 mass \%), the frequency distribution curves differ from the case with no nitrate in several significant ways. First, both the main and secondary peaks are shifted to less negative values upon $\mathrm{Ca}\left(\mathrm{NO}_{3}\right)_{2}$ addition, consistent with the decrease in average height change shown in Fig. 2a. Based on analysis of the fitting parameters $b_{1}$ and $b_{2}$ (see Fig. $4 \mathrm{a}$ ), it is suggested that $\mathrm{Ca}\left(\mathrm{NO}_{3}\right)_{2}$ reduces corrosion rates by suppressing both general recession (i.e., bulk dissolution) and fast localized corrosion at pitting sites, although the influence on localized corrosion is more pronounced. In addition, peak widths given by the parameters $c_{1}$ and $c_{2}$ also decreased, as shown in Fig. $4 \mathrm{~b}$, suggesting a decrease in uniform corrosion with $\mathrm{Ca}\left(\mathrm{NO}_{3}\right)_{2}$ dosage. A comparison of the frequency distribution curves in the absence of nitrate and in 1 mass $\% \mathrm{Ca}\left(\mathrm{NO}_{3}\right)_{2}$ highlights a shift of the secondary peak towards less negative values by around $7 \mu \mathrm{m}$, simultaneous with a decrease in the normalized frequency by more than one order of magnitude. Significantly, this indicates that low concentrations of $\mathrm{Ca}\left(\mathrm{NO}_{3}\right)_{2}$ inhibit corrosion processes by reducing the rate of vertical and lateral expansion of pits. Notably, further increasing the nitrate ion concentration to 10 mass \% resulted in a frequency distribution that closely resembled that of the nitrate-free conditions 


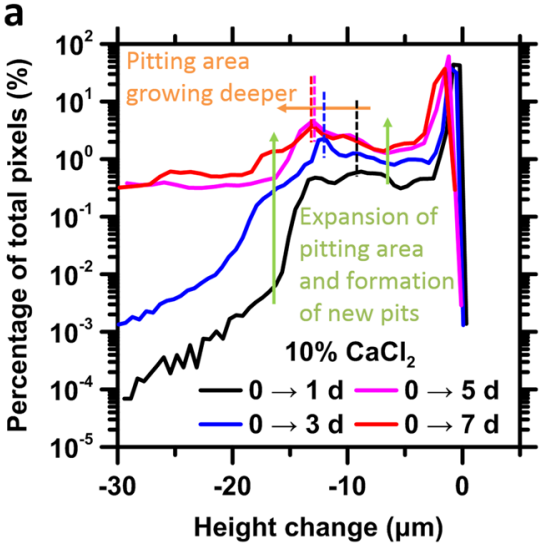

C

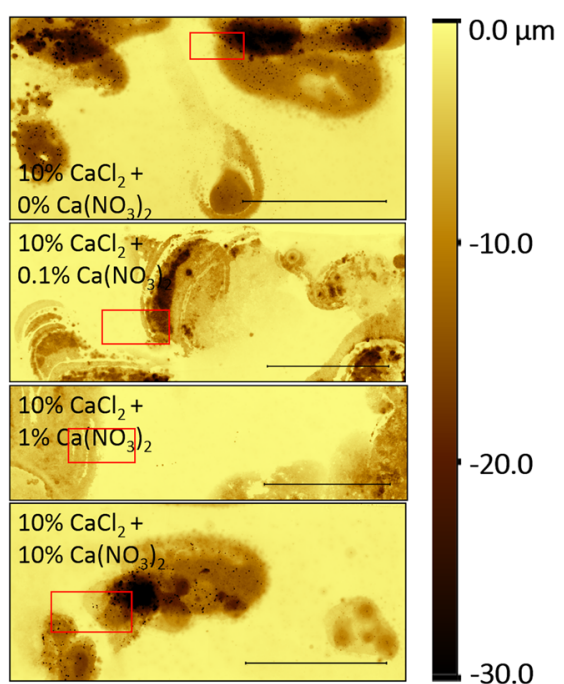

b

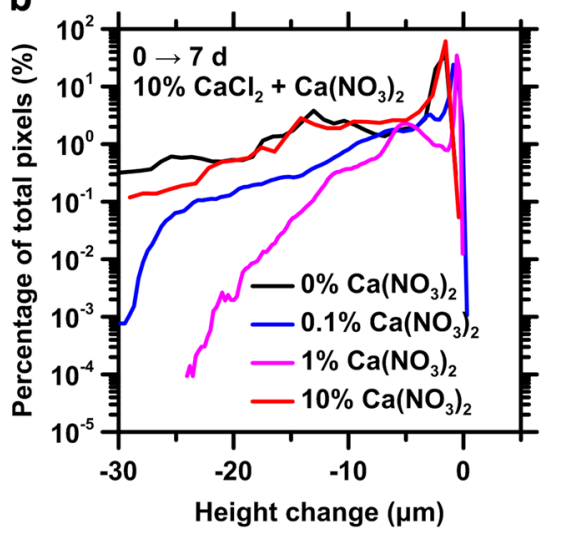

d

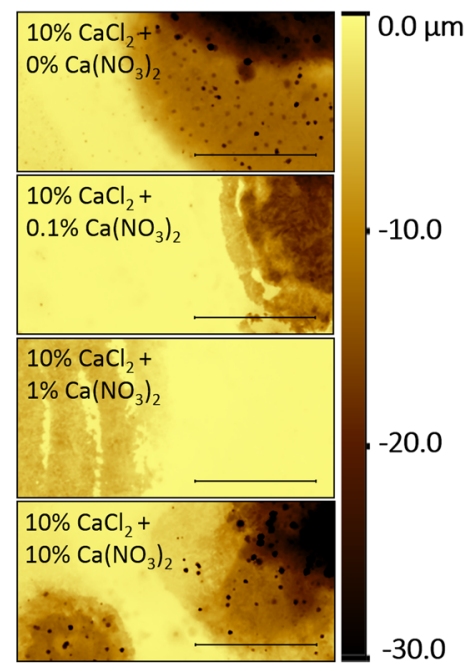

Fig. 3 The frequency distributions of height change for API P110 steel surfaces following exposure to: a 10 mass $\%$ CaCl ${ }_{2}$ brine up to 7 days, and $\mathbf{b} 10$ mass $\% \mathrm{CaCl}_{2}$ brine containing $0,0.1,1$, and 10 mass $\% \mathrm{Ca}\left(\mathrm{NO}_{3}\right)_{2}$ for duration of 7 days. The frequency is normalized to the total number of pixels in the image. In a, the secondary peaks representing pitting are labeled with dashed lines. The horizontal (orange) arrow indicates pit growth in the vertical coordinate and the vertical (green) arrows indicate lateral growth (and coalescence) of existing pits, and the formation of new pitting sites. The corresponding height change maps of $\mathbf{b}$ are shown in $\mathbf{c}$. The height change is calculated with respect to the initial, pristine steel surface. Selected areas marked with red box in c are shown in more detail in $\mathbf{d}$. The scale bars represent lengths of (c) $2 \mathrm{~mm}$ and (d) $500 \mu \mathrm{m}$

evidencing that increasing $\left[\mathrm{NO}_{3}{ }^{-}\right]$beyond an optimal value is detrimental.

To better elucidate the functions of $\mathrm{Ca}\left(\mathrm{NO}_{3}\right)_{2}$ as a corrosion inhibitor, the VSI observations were augmented by SEM visualizations of corroding surfaces. First, as shown in Fig. 5a, API P110 steel presents a single-phase martensitic microstructure with a grain size of around $10 \mu \mathrm{m}$. Visualization of corroded microstructures reveals that pits are localized at pre-austenite grain boundaries, for example, as shown in Fig. 5b and S2, consistent with previous observations. ${ }^{32-35}$ It is generally thought that in the presence of $\mathrm{Cl}^{-}$ions, surface defect sites, for example, grain boundaries, and secondary-phase inclusions are most vulnerable to pitting. ${ }^{33,36,37}$ As pitting initiates, the release of iron in the form of $\mathrm{Fe}^{2+}$ promotes local acidification within the pit following the reaction: (1) $\mathrm{Fe}-2 \mathrm{e}^{-} \rightarrow \mathrm{Fe}^{2+}$, (2) $\mathrm{Fe}^{2+}+\mathrm{H}_{2} \mathrm{O} \rightarrow \mathrm{Fe}$ $(\mathrm{OH})^{+}+\mathrm{H}^{+}$, and (3) $\mathrm{Fe}(\mathrm{OH})^{+}+\mathrm{H}_{2} \mathrm{O} \rightarrow \mathrm{Fe}(\mathrm{OH})_{2}+\mathrm{H}^{+}$, resulting in an acidic $\mathrm{pH}$ in the bottom of the pit. ${ }^{38-41}$ The high local $\mathrm{H}^{+}$and $\mathrm{Fe}^{2+}$ activities at the bottom of the pit-and the corresponding gradient that develops-results in the transport of anions towards the pitted area. The concentration gradient of ions induces the development of an electrochemical potential difference between the pit bottom and the surface of the steel that can be as high as hundreds of millivolts. ${ }^{42,43}$

The pit morphologies observed in Fig. 5 are significantly smaller than stable pits that form on surface of passivated steels. ${ }^{44}$ Further, as shown in Fig. 5b, herein, a rapidly corroding zone is noted to form around a central pit whose radius is several times larger than that of the pit itself, that is, in terms of its radial dimension. A line profile (Fig. 5e) drawn through the center of the pit-using the VSI topography image (Fig. 5c)-shows that the surrounding radial area ("basin") encompasses a radius of $80 \mu \mathrm{m}$, whereas the central pit only achieves a maximum radius of $17 \mu \mathrm{m}$ (and a depth of around $3.5 \mu \mathrm{m})$. It is the formation of such radial basins that explains the secondary peaks evident in the frequency distribution curves (Fig. 3).

By simulating the effects of anodic corrosion on the evolution of the pit geometry, we attribute the formation of these radial basins as being the result of near-surficial, lateral expansion of the pit mouth (e.g., see Fig. 5b-f), for example, as observed in the corrosion of AISI 1045 steel by Guo et al. ${ }^{30}$ As such, Fig. 6 shows the simulated local potential distribution and resulting electric field strength distribution and the implications on the formation 
a

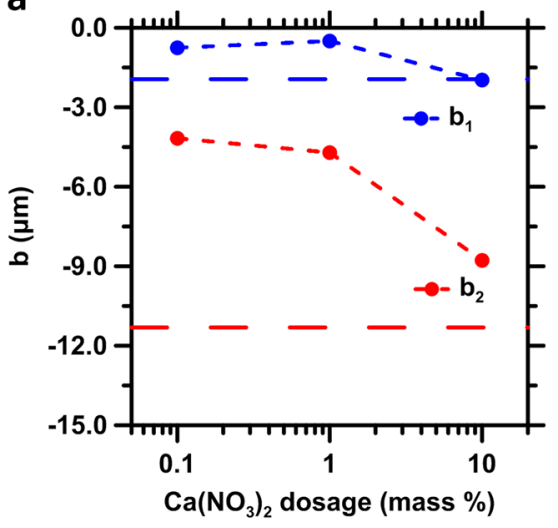

b

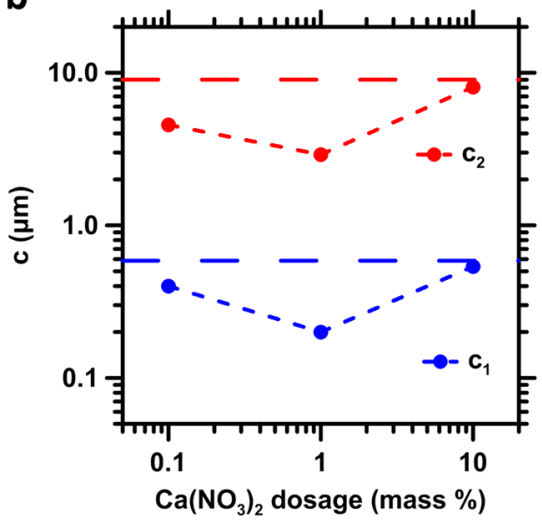

Fig. 4 A summary of the Gaussian fitting parameters: a peak positions $b_{1}, b_{2}$, and $\mathbf{b}$ peak widths $c_{1}, c_{2}$ for the frequency distributions of height change for steel surfaces following exposure to 10 mass $\% \mathrm{CaCl}_{2}$ brine containing $0,0.1,1$, and 10 mass $\% \mathrm{Ca}$ $\left(\mathrm{NO}_{3}\right)_{2}$ for 7 days. The subscripts 1 (blue) and 2 (red) denote the main peak and secondary peak, respectively. The blue and red horizontal dashed lines identify baseline values in $\mathrm{Ca}\left(\mathrm{NO}_{3}\right)_{2}$-free systems

of the radial basin using a finite element approach (COMSOL Multiphysics, ver. 4.4). The simulation considers a hemispherical pit as shown in Fig. 6a. This represents a typical morphology for a pit $^{36}$ and resembles the central pit shown in Fig. 5b, c. Upon the initial formation of the hemispherical pit (e.g., perhaps at a MnS site), fast dissolution results in development of an electrochemical potential difference between the pit bottom and pit mouth. Herein, the pit bottom serves as the anode with an assumed potential that is $100 \mathrm{mV}$ more anodic relative to the pit mouth that serves as a cathode. The potential along the pit wall is assumed following a simple linear distribution written as:

$\Phi_{\text {wall }}=\frac{\left(\Phi_{\text {bottom }}-\Phi_{\text {mouth }}\right)}{L} x-\Phi_{\text {mouth }}$,

where $\Phi_{\text {wall }}$ is the potential of the pit wall at a depth of $x, \Phi_{\text {bottom }}$ is $100 \mathrm{mV}$ at the pit bottom where $x=L$, and $\Phi_{\text {mouth }}$ is referenced as zero. Figure $6 \mathrm{~b}, \mathrm{c}$ show the simulated spatial distributions of the potential and normalized electric field governed by the harmonic condition: $\nabla^{2} \Phi=0$, in both the solution and the adjacent steel surface, respectively. The simulation indicates that the development of an electric field concentration at the pit mouth results from its convexity or curvature, for example, similar to a stress concentration (see arrows in Fig. 6c). Significantly, Fig. 6c highlights that the electric field concentration affects both the steel surface at the pit mouth and the solution in the vicinity. In unpassivated alloys, this forebodes the fast expansion of the pit mouth due to an electrostatically induced change in interfacial tension at the steel-solution interface. ${ }^{45}$ At later times, however, such lateral expansion is expected to hinder pit deepening due to attenuation of the local concentration gradients of ions in the pit. This suggests that in simply oxidized, that is, non-passivated systems, the pit morphology shown in Fig. 5 is unlikely to sustain a mass-transport limiting current that is required for stable pit growth. Therefore, the potential and concentration gradients will disappear following the discontinuance of the pit growth, and a general corrosion rate can be applied to both the pit wall and the pit mouth. Figure $6 \mathrm{~d}$ shows the morphology evolution of an "arrested" pit with the same dissolution rate $\left(5 \mathrm{~A} / \mathrm{m}^{2}\right)^{46}$ along the pit wall and the open surface. This indicates that the expansion of the pit mouth is induced as a function of its high surface to volume ratio, that is, local curvature. This suggests that the corrosion pits that form will eventually transition into "recessed basins" rather than the stable pits that are observed in passivated alloys. $^{36,44,47}$

The radial basins discussed above were also found on steel surfaces reacted with 10 mass $\% \mathrm{CaCl}_{2}$ containing 1 mass $\% \mathrm{Ca}$ $\left(\mathrm{NO}_{3}\right)_{2}$ solution following $20 \mathrm{~h}$ of contact (Fig. 5d). Although the central pit depths are similar across $\mathrm{Ca}\left(\mathrm{NO}_{3}\right)_{2}$-free and $\mathrm{Ca}\left(\mathrm{NO}_{3}\right)_{2}-$ dosed systems (i.e., $3.5 \mu \mathrm{m}$ ), the central pit features a much smaller opening $\left(8 \mu \mathrm{m}\right.$ in diameter) when $\mathrm{Ca}\left(\mathrm{NO}_{3}\right)_{2}$ is present. Furthermore, unlike the case with no added $\mathrm{Ca}\left(\mathrm{NO}_{3}\right)_{2}$ (Fig. $5 \mathrm{C}$, e), the pits formed in $\mathrm{Ca}\left(\mathrm{NO}_{3}\right)_{2}$-dosed environments are less well developed. For example, first, the region of enhanced corrosion around the central pit is smaller (20 vs. $80 \mu \mathrm{m}$ in radius). Second, the average vertical depression of this area is considerably smaller, that is, 0.8 vs. $1.8 \mu \mathrm{m}$. It is interesting to note that a slight increase in height around the pitting area is also apparent, for example, due to localized formation and attachment of corrosion/oxidation products. This is consistent with the proposed corrosion inhibition mechanism of $\mathrm{NO}_{3}{ }^{-}$ions. Specifically, nitrate is thought to consume released $\mathrm{Fe}^{2+}$ species by oxidizing it to $\mathrm{Fe}^{3+}$. This results in the precipitation of solid corrosion products such as $\mathrm{Fe}$ oxides and hydroxides. ${ }^{10,12}$ Consequently, the pitting site is isolated by the deposition of such precipitation products and thereby protected from further corrosion by reducing its access to electrolytes in solution. The deposition of corrosion products at the pit mouth is also expected to reduce its convexity, and electrical field concentration at the pit mouth-resulting in the formation of more diffuse, albeit shallower basin depressions as evidenced in Fig. $5 \mathrm{~d}$, f. Furthermore, the migration and concentration of $\mathrm{NO}_{3}{ }^{-}$anions towards the anodically corroding regions is expected to follow the electric field intensity and compete with the transport of $\mathrm{Cl}^{-}$to the same sites. These actions alleviate the $\mathrm{Cl}^{-}$concentration at anodic sites and mitigate $\mathrm{Cl}^{-}$induced localized corrosion around pitting sites in the presence of $\mathrm{Ca}\left(\mathrm{NO}_{3}\right)_{2} \cdot{ }^{48,49}$ This explains why shallower pits, and smaller basins develop in $\mathrm{Ca}\left(\mathrm{NO}_{3}\right)_{2}$ containing systems at moderate dosages. This interpretation is consistent with the trends obtained from the frequency distribution curves above which highlight: (1) a shift in the position of the secondary peak towards less negative values, and (2) a reduction in normalized frequency of pixels associated with secondary peaks. Contrastingly, when the $\mathrm{Ca}\left(\mathrm{NO}_{3}\right)_{2}$ concentration is further increased, however, the oxidizing potential of the bulk solution also increases. It is for this reason that high dosages of $\mathrm{Ca}\left(\mathrm{NO}_{3}\right)_{2}$ (10 mass \%) enhance the oxidative dissolution of iron and compromise the corrosion inhibition effect that is offered by $\mathrm{Ca}\left(\mathrm{NO}_{3}\right)_{2}$ additions at lower concentrations. ${ }^{50}$

As such, in closing this paper has comprehensively examined the corrosion of API P110 steel in concentrated halide environments in the presence of $\mathrm{Ca}\left(\mathrm{NO}_{3}\right)_{2}$ as a corrosion inhibitor. Special focus is placed on examining the evolution of corroding topographies-at unparalleled resolution-across a large field of view (FOV) using VSI for samples reacted in a controlled environment under isothermal conditions. Careful analysis of 
a

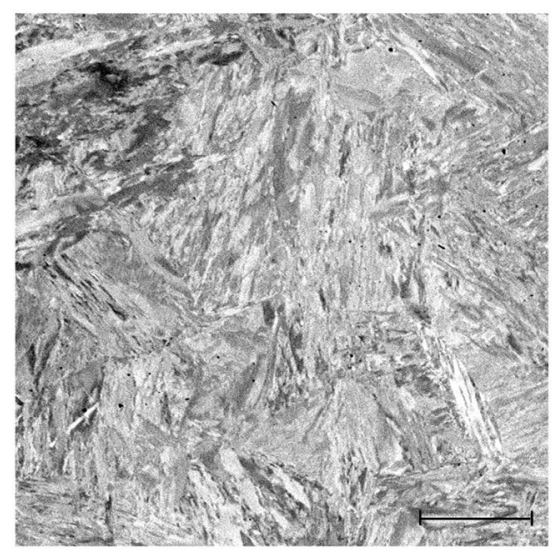

C

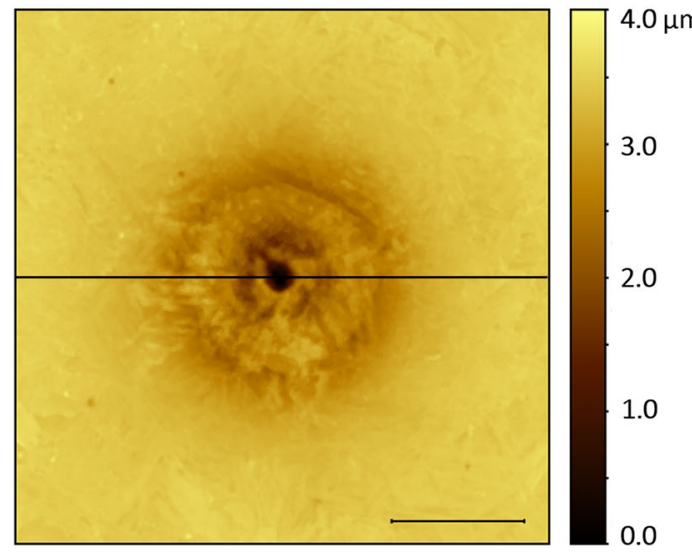

e

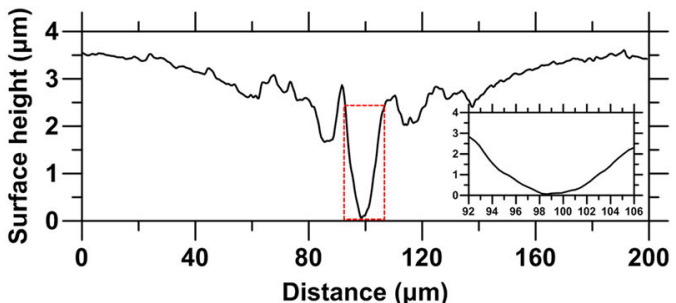

b

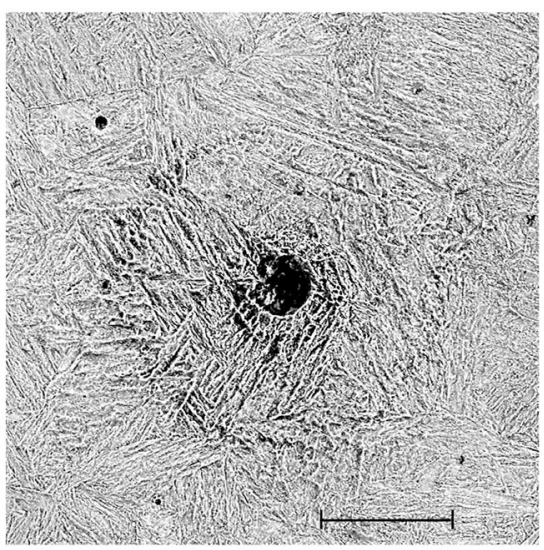

d

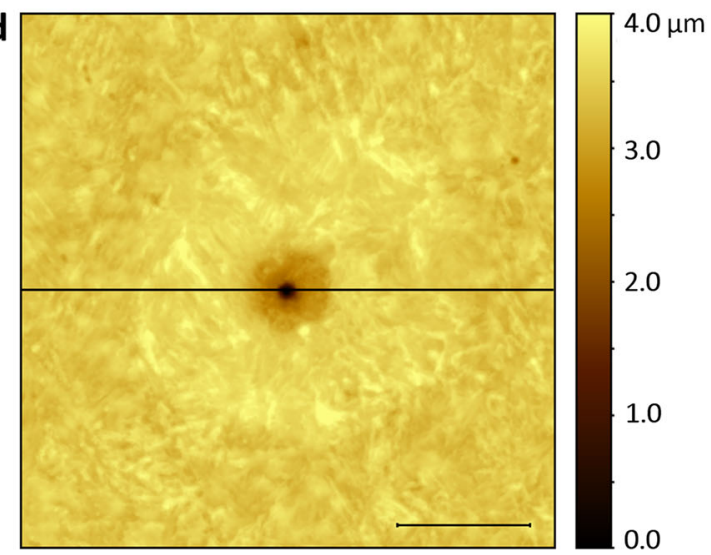

f

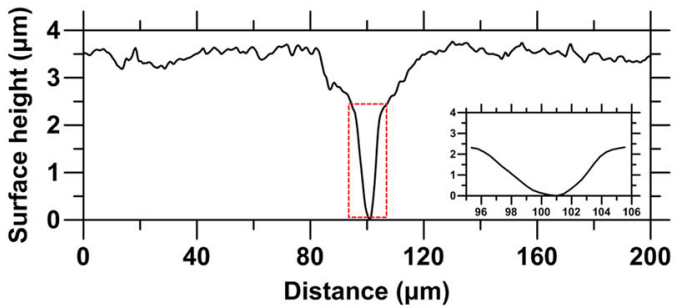

Fig. 5 SEM micrographs of: $\mathbf{a}$ an as-polished API P110 steel surface, showing its martensitic microstructure, and, $\mathbf{b}$ a representative pit that forms on a steel surface reacted with 10 mass $\% \mathrm{CaCl}_{2}$ brine for $20 \mathrm{~h}$ showing a radial depression that forms around a central pitting site. VSI topography images of a representative pit and its vicinity formed following contact with: $\mathbf{c} 10$ mass $\% \mathrm{CaCl}_{2}$ brine, and, $\mathbf{d} 10$ mass $\% \mathrm{CaCl}_{2}+1$ mass $\% \mathrm{Ca}\left(\mathrm{NO}_{3}\right)_{2}$ solution for $20 \mathrm{~h}$, corresponding line profiles along the central lines are shown in e, $\mathbf{f}$ with inserted profiles of pit bottoms. The VSI images were acquired using a $\times 20$ Mirau objective with a lateral resolution of $0.47 \mu \mathrm{m}$. The scale bars represent lengths of a $10 \mu \mathrm{m}, \mathbf{b}$ $30 \mu \mathrm{m}$, and $\mathbf{c}$, d $50 \mu \mathrm{m}$

surface topographies, pixel-by-pixel, indicates that while moderate concentrations of $\mathrm{Ca}\left(\mathrm{NO}_{3}\right)_{2}$ can effectively inhibit corrosion in the presence of $\mathrm{Cl}^{-}$and $\mathrm{Br}^{-}$, such inhibition is compromised at higher dosages due to the significant oxidizing potential of the bulk solution. By statistical analysis of surface height data ("frequency distributions"), it is highlighted that $\mathrm{Ca}\left(\mathrm{NO}_{3}\right)_{2}$ suppresses localized corrosion primarily, although a measurable effect on general corrosion was also observed. Localized corrosion is manifested by a fast dissolution zone (i.e., basin), which forms in the vicinity of central pitting sites. Simulations of the electrochemical evolutions within a pit suggest that these features arise from the fast expansion of the pit mouth whose local curvature results in the concentration of an electric field distribution. The mechanism of $\mathrm{NO}_{3}{ }^{-}$inhibition is consistent with this model such in the presence of nitrate the oxidation of $\mathrm{Fe}^{2+}$ to $\mathrm{Fe}^{3+}$ leads to the precipitation and deposition of Fe oxides and hydroxides, hindering further pit expansion. To the best of our knowledge, this is the first time that the inhibition effect of $\mathrm{Ca}\left(\mathrm{NO}_{3}\right)_{2}$ has been evidenced from quantitative and statistical analysis of corroding surfaces. These findings provide new insights regarding the role of the water chemistry and inhibitor dosage to suppress steel corrosion evolutions in aggressive halide-rich environments.

\section{METHODS}

Materials: Preparation of steel surfaces and brines

Commercially available API P110 steel (McMahon Steel Supply) with a nominal composition of C $(0.25 \%)$, Si $(0.36 \%), M n(1.24 \%), P(0.013 \%)$, S $(0.004 \%), \mathrm{Cr}(0.50 \%), \mathrm{Al}(0.03 \%)$, and $\mathrm{Fe}(97.6 \%)$ was used. During its processing, this steel is quenched, giving rise to a microstructure that is characterized as monophasic martensite. The steel was machined into coupons having dimensions of $6 \mathrm{~mm} \times 6 \mathrm{~mm} \times 4 \mathrm{~mm}$ (length $\times$ width $\times$ height) and then embedded in epoxy resin to facilitate handling, while leaving only the top surface of the steel exposed. The steel surface was 


\section{a}

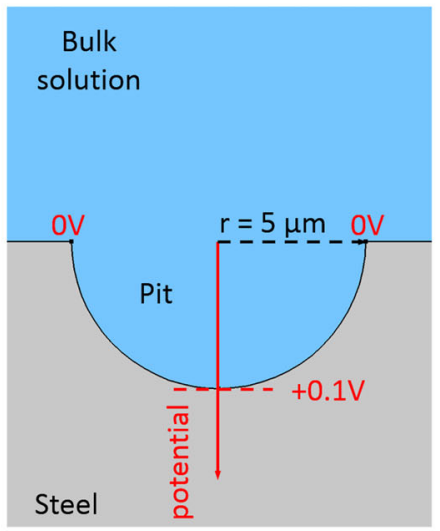

C

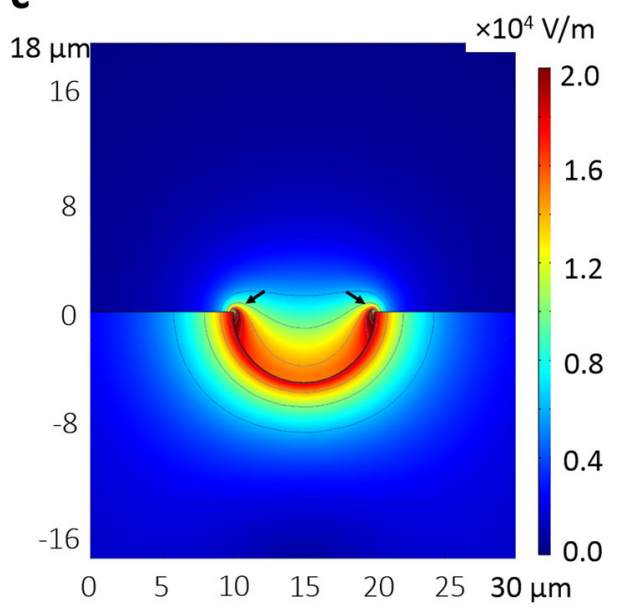

b

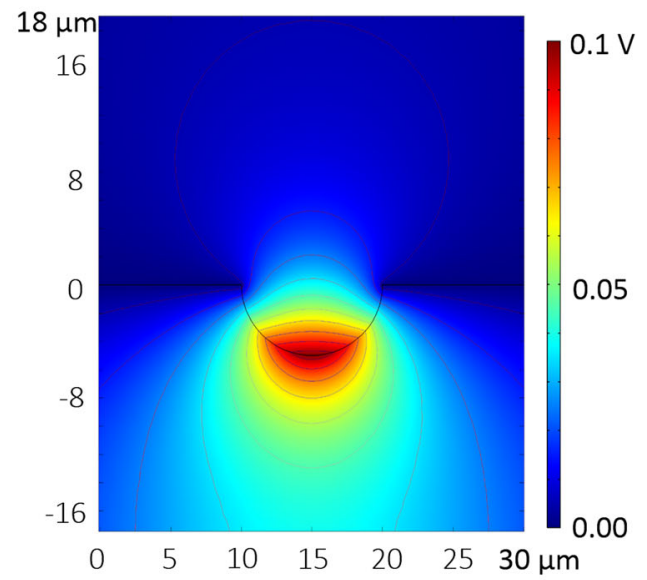

d

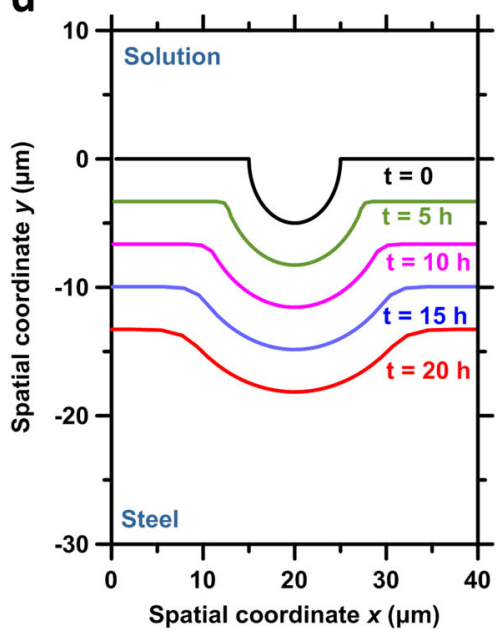

Fig. 6 a A schematic showing the pit geometry and the applied potential profile, $\mathbf{b}$ the simulated potential distribution with isopotential contours in the steel and in the vicinity of the pit, $\mathbf{c}$ the simulated electric field strength distribution with isofield contours, the arrows indicate an electric field concentration at the pit mouth due to a convexity, and $\mathbf{d}$ the morphology evolution of an "arrested" pit

then polished successively using SiC sand paper and diamond paste until it featured a surface roughness $\left(S_{z}\right)$ of $1 \mu \mathrm{m}$. Thereafter, the sample was ultrasonically rinsed with ethanol and deionized (DI) water for $3 \mathrm{~min}$, and stored in a desiccator after being dried under an air stream. The epoxymounted samples were secured on kinematic mounts (Thorlabs) to maintain imaging positions within $\pm 3 \mu \mathrm{m}$ and $\pm 1 \mu \mathrm{m}$ over the course of the experiments.

Brines were prepared by adding ACS reagent grade $\mathrm{CaCl}_{2}, \mathrm{CaBr}_{2}$, and $\mathrm{Ca}$ $\left(\mathrm{NO}_{3}\right)_{2}$ to $\mathrm{DI}$ water to produce $10 \% \mathrm{CaCl}_{2}$ or $10 \% \mathrm{CaBr}_{2}$ solutions that contain $0 \%, 0.1 \%, 1 \%$, and $10 \% \mathrm{Ca}\left(\mathrm{NO}_{3}\right)_{2}$ (mass basis). The measured $\mathrm{pH}$ 's of these solutions are listed in Table 1. These concentrations were chosen to encompass a wide range of $\mathrm{Ca}\left(\mathrm{NO}_{3}\right)_{2}$ concentrations to assess the effect (s) of a diversity of dosage levels, and potential changes in inhibition mechanisms and the resulting effects on corrosion evolutions.

\section{Methods: Surface topography evolutions captured using VSI}

Corrosion behavior under brine immersion was monitored for up to 7 days at $25 \pm 0.2^{\circ} \mathrm{C}$ in a temperature-controlled environment. The surfaces of the steel samples were exposed to brine volumes on the order of $135 \pm 2 \mathrm{~mL}$ resulting in a nominal surface-to-volume ratio $\left(\mathrm{mm}^{-1}\right)$ of 1/9000. Prior to immersion, approximately half of the sample surface was covered with a peelable silicone mask (Silicone Solutions SS-380) to preserve a portion of the steel surface in a pristine state, which serves as the reference surface. As a result, absolute height changes can be ascertained by comparing the reference surface with the reacted (i.e., exposed to brine) surface. The effectiveness of this procedure is illustrated in Fig. 7, which shows VSI images of a steel surface before and following immersion. To assess the chemical stability of the silicone mask, concentrations of dissolved silicon in contact with brine were measured using a Perkin-Elmer Avio 200 inductively coupled plasma optical emission spectrometer. Measured $\mathrm{Si}$ concentrations ranged from 0.13 to $1.14 \mathrm{ppm}$, with an average value of $0.64 \mathrm{ppm}$. This level of silicon abundance and negligible changes in the silicon mask's surface topography following immersion indicate that it is inert up on exposure to the brine environment.

The steel's surface topography was monitored following its contact with the brines at time intervals of $0,1,3,5$, and 7 days. At each time point (except 0 days), any corrosion products that may have formed on the steel surface were removed following ASTM G1. ${ }^{26}$ Thereafter, the silicon adhesive was peeled cleanly and the surface topography was examined using VSI. The VSI used a Zygo NewView 8200 fitted with a $5 \times$ Mirau objective having a numerical aperture of 0.13 and offering a lateral (in the $x$ and $y$ directions) resolution of $1.63 \mu \mathrm{m}$. The lateral resolution is determined by both the objective and the spatial sampling of the camera (1024 pixel $\times 1024$ pixel in one FOV, that is, $1.67 \mathrm{~mm} \times$ $1.67 \mathrm{~mm}$ ). The resolution in the $z$-direction is estimated to be on the order of $\pm 2 \mathrm{~nm}$ based on analysis of a NIST traceable step-height standard. Imaging of the steel surface that encompassed an area on the order of $12-15 \mathrm{~mm}^{2}$ was carried out by stitching multiple overlapping sub-images that were acquired sequentially along a grid map. It should be noted that the use of kinematic mounts as described above enabled repeatability in lateral positioning on the order of $\pm 3 \mu \mathrm{m}$ which is similar to the resolution of images acquired using this specific $(5 x)$ Mirau objective. 


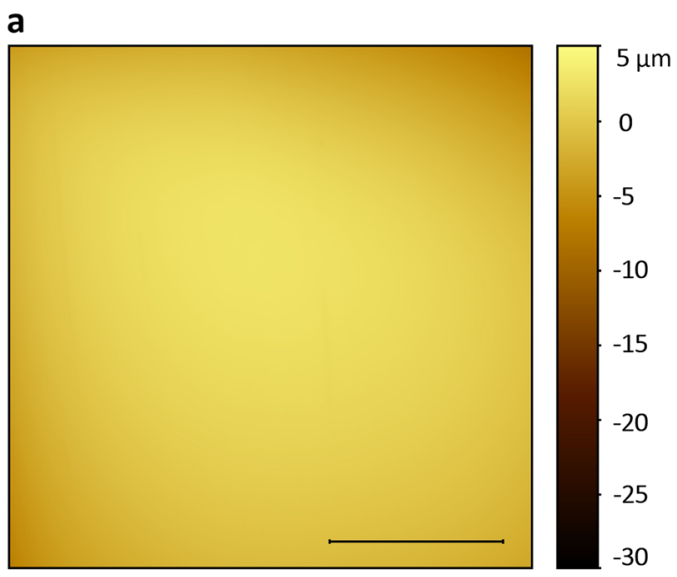

b

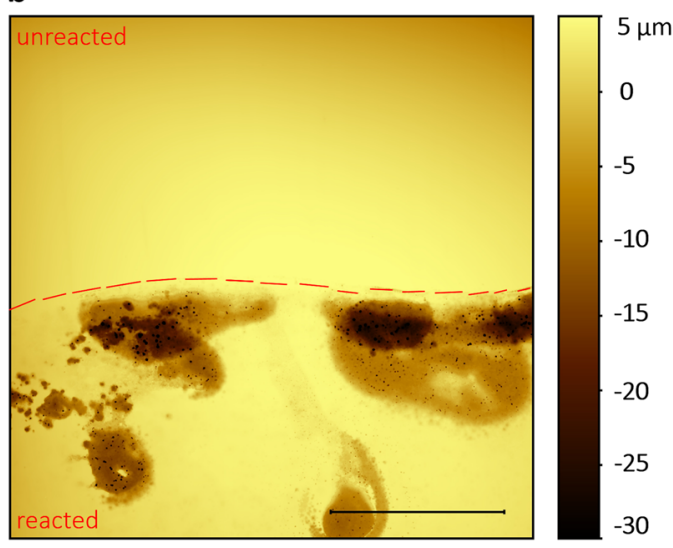

Fig. 7 Representative VSI topography maps of API P110 steel surface obtained $\mathbf{a}$ as-polished, and $\mathbf{b}$ following immersion in 10 mass $\% \mathrm{CaCl}_{2}$ brine for 7 days. The boundary between the unreacted ("masked") surface and reacted surface is labeled by the dashed line. The scale bars represent a length of $2 \mathrm{~mm}$

\section{Analysis of 3D surface topography data}

The 3D surface topography images (i.e., height maps) obtained using VSI were processed and analyzed using Matlab ${ }^{\circledR}$ R2017b and rendered using Gwyddion. ${ }^{27}$

Quantification of corrosion rates from average height change: The absolute surface height change at time $t, \Delta z_{t}$, was determined from the difference in average heights of the reacted $(s)$ and reference $(r)$ surfaces, $z_{\mathrm{t}}^{\mathrm{s}}$ and $z_{\mathrm{t}}^{\mathrm{r}}$, respectively, at time $t$, as compared to that at time 0 , as given by:

$\Delta z_{\mathrm{t}}=\left(z_{\mathrm{t}}^{\mathrm{s}}-z_{\mathrm{t}}^{\mathrm{r}}\right)-\left(z_{0}^{\mathrm{s}}-z_{0}^{\mathrm{r}}\right)$

Hence, at time $t=0$, the absolute height change, $\Delta z_{0}=0$, whereas a negative $\Delta z_{t}$ would imply a net decrease in surface height at a given pixel location, that is, loss of metal due to corrosion. Although corrosion is expected to result in the deposition of corrosion products which have a higher molar volume compared to the native alloy, and hence result in a height increase, the removal of corrosion products before each imaging sequence eliminates ambiguities in the interpretation of height changeresulting in a height decrease, in time.

Frequency distribution of height change: In addition to surface height changes, the spatial distribution of height change was assessed-pixel by pixel-across a given surface. This offers insights into the frequency distributions of reaction (corrosion) rates. The $3 \mathrm{D}$ images, following alignment in the vertical direction using the known reference surface, were each subtracted pixel-by-pixel from that obtained at $t=0$, to give the height change map. The frequency distribution of height changes, normalized to the total number of pixels-which is on the order of $10^{7}$ pixels-is then plotted for each time interval.

\section{DATA AVAILABILITY}

The analysis scripts and datasets generated during and/or analyzed over the course of the title study are available from the corresponding author up on reasonable request.

\section{ACKNOWLEDGEMENTS}

The authors acknowledge financial support for this research provisioned by: The National Science Foundation (CMMI: 1401533) and Yara Industrial Nitrates. The contents of this paper reflect the views and opinions of the authors who are responsible for the accuracy of data presented. This research was carried out in the Laboratory for the Chemistry of Construction Materials $\left(\mathrm{LC}^{2}\right)$. As such, the authors gratefully acknowledge the support that has made these laboratories and their operations possible.

\section{AUTHOR CONTRIBUTIONS}

E.C.L.P., X.C., and G.N.S. designed the research. S.D., E.C.L.P., and X.C. performed the research. X.C., S.D., E.C.L.P., and G.N.S. analyzed the data. All authors contributed to the writing of the paper and approval of the manuscript in its current form.

\section{ADDITIONAL INFORMATION \\ Competing interests: The authors declare no competing interests.}

Publisher's note: Springer Nature remains neutral with regard to jurisdictional claims in published maps and institutional affiliations.

\section{REFERENCES}

1. Downs, J. Formate brines: novel drilling and completion fluids for demanding environments. SPE Repr. Ser. https://doi.org/10.2118/25177-MS (1993).

2. Kadhim, F. S. Investigation of carbon steel corrosion in water base drilling mud. Mod. Appl. Sci. 5, 224 (2011).

3. Liu, Y. et al. Corrosion mechanism of ${ }^{13} \mathrm{Cr}$ stainless steel in completion fluid of high temperature and high concentration bromine salt. Appl. Surf. Sci. 314, 768-776 (2014).

4. Liu, Y., Xu, L. N., Zhu, J. Y. \& Meng, Y. Pitting corrosion of ${ }^{13} \mathrm{Cr}$ steel in aerated brine completion fluids. Mater. Corros. 65, 1096-1102 (2014).

5. Kaneko, M. \& Isaacs, H. S. Pitting of stainless steel in bromide, chloride and bromide/chloride solutions. Corros. Sci. 42, 67-78 (2000).

6. Pinkus, P., Eliezer, D. \& Itzhak, D. The influence of alkali-halide additions on the stress corrosion cracking of an austenitic stainless steel in $\mathrm{MgCl}^{2}$ solution. Corros. Sci. 21, 417-423 (1981).

7. Tanno, K., Itoh, M., Takahashi, T., Yashiro, H. \& Kumagai, N. The corrosion of carbon steel in lithium bromide solution at moderate temperatures. Corros. Sci. 34, 1441-1451 (1993).

8. Lee, S. U., Ahn, J. C., Kim, D. H., Hong, S. C. \& Lee, K. S. Influence of chloride and bromide anions on localized corrosion of $15 \% \mathrm{Cr}$ ferritic stainless steel. Mater. Sci. Eng. A 434, 155-159 (2006).

9. Królikowski, A. \& Kuziak, J. Impedance study on calcium nitrite as a penetrating corrosion inhibitor for steel in concrete. Electrochim. Acta 56, 7845-7853 (2011).

10. Justnes, H. in. Innovations and Developments in Concrete Materials and Construction (eds Dhir, R. K., Hewlett, P. C., \& Csetenyi, L. J.) 391-401 (Thomas Telford Publishers, London, 2002).

11. Ngala, V. T., Page, C. L. \& Page, M. M. Corrosion inhibitor systems for remedial treatment of reinforced concrete. Part 1: calcium nitrite. Corros. Sci. 44, 2073-2087 (2002)

12. Gaidis, J. M. Chemistry of corrosion inhibitors. Cem. Concr. Compos. 26, 181-189 (2004).

13. Dhouibi, L., Triki, E. \& Raharinaivo, A. The application of electrochemical impedance spectroscopy to determine the long-term effectiveness of corrosion inhibitors for steel in concrete. Cem. Concr. Compos. 24, 35-43 (2002).

14. Al-Amoudi, O. S. B., Maslehuddin, M., Lashari, A. N. \& Almusallam, A. A. Effectiveness of corrosion inhibitors in contaminated concrete. Cem. Concr. Compos. 25, 439-449 (2003).

15. Lasaga, A. C. \& Luttge, A. Variation of crystal dissolution rate based on a dissolution stepwave model. Science 291, 2400-2404 (2001).

16. Kumar, A., Reed, J. \& Sant, G. Vertical scanning interferometry: a new method to measure the dissolution dynamics of cementitious minerals. J. Am. Ceram. Soc. 96, 2766-2778 (2013). 
17. Davis, K. J. \& Lüttge, A. Quantifying the relationship between microbial attachment and mineral surface dynamics using vertical scanning interferometry (VSI). Am. J. Sci. 305, 727-751 (2005).

18. Waters, M. S. et al. Simultaneous interferometric measurement of corrosive or demineralizing bacteria and their mineral interfaces. Appl. Environ. Microbiol. 75, 1445-1449 (2009).

19. Rigg, T. \& Rahaman, M. S. Dissolution of ferritic stainless steel scrap in hydrochloric acid. Can. J. Chem. Eng. 49, 550-551 (1971).

20. Lister, D. H., Davidson, R. D. \& McAlpine, E. The mechanism and kinetics of corrosion product release from stainless steel in lithiated high temperature water. Corros. Sci. 27, 113-140 (1987).

21. Chao, C. Y., Lin, L. F. \& Macdonald, D. D. A point defect model for anodic passive films. I. Film growth kinetics. J. Electrochem. Soc. 128, 1187-1194 (1981).

22. Sánchez, J., Fullea, J., Andrade, C., Gaitero, J. J. \& Porro, A. AFM study of the early corrosion of a high strength steel in a diluted sodium chloride solution. Corros. Sci. 50, 1820-1824 (2008).

23. Sekine, I., Hayakawa, T., Negishi, T. \& Yuasa, M. Analysis for corrosion behavior of mild steels in various hydroxy acid solutions by new methods of surface analyses and electrochemical measurements. J. Electrochem. Soc. 137, 3029-3033 (1990).

24. Li, J. L., Ma, H. X., Zhu, S. D., Qu, C. T. \& Yin, Z. F. Erosion resistance of $\mathrm{CO}_{2}$ corrosion scales formed on API P110 carbon steel. Corros. Sci. 86, 101-107 (2014).

25. Zhu, S. D. et al. Failure analysis of P110 tubing string in the ultra-deep oil well. Eng. Fail. Anal. 18, 950-962 (2011).

26. ASTM G1-90. Standard practice for preparing, cleaning, and evaluating corrosion test specimens. ASTM Stand. https://doi.org/10.1520/g0001-03r17e01 (1990).

27. Nečas, D. \& Klapetek, P. Gwyddion: an open-source software for SPM data analysis. Cent. Eur. J. Phys. 10, 181-188 (2012).

28. Valcarce, M. B. \& Vázquez, M. Carbon steel passivity examined in alkaline solutions: the effect of chloride and nitrite ions. Electrochim. Acta 53, 5007-5015 (2008).

29. Deyab, M. A. \& Abd El-Rehim, S. S. Inhibitory effect of tungstate, molybdate and nitrite ions on the carbon steel pitting corrosion in alkaline formation water containing $\mathrm{Cl}^{-}$ion. Electrochim. Acta 53, 1754-1760 (2007).

30. Guo, P. et al. Direct observation of pitting corrosion evolutions on carbon steel surfaces at the nano-to-micro-scales. Sci. Rep. 8, 7990 (2018).

31. Hoar, T. P. \& Jacob, W. R. Breakdown of passivity of stainless steel by halide ions. Nature 216, 1299-1301 (1967)

32. Streicher, M. A. Pitting corrosion of ${ }^{18} \mathrm{Cr}^{-}{ }^{8} \mathrm{Ni}$ stainless steel. J. Electrochem. Soc. 103, 375-390 (1956).

33. Marcus, P., Maurice, V. \& Strehblow, H. -H. Localized corrosion (pitting): a model of passivity breakdown including the role of the oxide layer nanostructure. Corros. Sci. 50, 2698-2704 (2008).

34. Nilsson, J. O. \& Wilson, A. Influence of isothermal phase transformations on toughness and pitting corrosion of super duplex stainless steel SAF 2507. Mater. Sci. Technol. 9, 545-554 (1993).

35. Szklarska-Smialowska, Z. \& Janik-Czachor, M. Pitting corrosion of ${ }^{13} \mathrm{Cr}$-Fe alloy in $\mathrm{Na}_{2} \mathrm{SO}_{4}$ solutions containing chloride ions. Corros. Sci. 7, 65-72 (1967).

36. Frankel, G. S. Pitting corrosion of metals a review of the critical factors. J. Electrochem. Soc. 145, 2186-2198 (1998).
37. Tsutsumi, Y., Nishikata, A. \& Tsuru, T. Pitting corrosion mechanism of type 304 stainless steel under a droplet of chloride solutions. Corros. Sci. 49, 1394-1407 (2007).

38. Park, J. O. \& Böhni, H. Local pH measurements during pitting corrosion at MnS inclusions on stainless steel. Electrochem. Solid-State Lett. 3, 416-417 (2000).

39. Fregonese, M., Idrissi, H., Mazille, H., Renaud, L. \& Cetre, Y. Initiation and propagation steps in pitting corrosion of austenitic stainless steels: monitoring by acoustic emission. Corros. Sci. 43, 627-641 (2001).

40. Williams, D. E., Newman, R. C., Song, Q. \& Kelly, R. G. Passivity breakdown and pitting corrosion of binary alloys. Nature 350, 216-219 (1991).

41. Mankowski, J. \& Szklarska-Smialowska, Z. Studies on accumulation of chloride ions in pits growing during anodic polarization. Corros. Sci. 15, 493-501 (1975).

42. Butler, G., Stretton, P. \& Beynon, J. G. Initiation and growth of pits on high-purity iron and its alloys with chromium and copper in neutral chloride solutions. $\mathrm{Br}$. Corros. J. 7, 168-173 (1972).

43. Walton, J. C. Mathematical modeling of mass transport and chemical reaction in crevice and pitting corrosion. Corros. Sci. 30, 915-928 (1990).

44. Ernst, P. \& Newman, R. C. Pit growth studies in stainless steel foils. I. Introduction and pit growth kinetics. Corros. Sci. 44, 927-941 (2002).

45. Merola, C. et al. In situ nano- to microscopic imaging and growth mechanism of electrochemical dissolution (e.g., corrosion) of a confined metal surface. Proc. Natl. Acad. Sci. USA 114, 9541-9546 (2017).

46. Cáceres, L., Vargas, T. \& Herrera, L. Influence of pitting and iron oxide formation during corrosion of carbon steel in unbuffered $\mathrm{NaCl}$ solutions. Corros. Sci. $\mathbf{5 1}$ 971-978 (2009)

47. Chen, X., Ebert, W. L. \& Indacochea, J. E. Electrochemical corrosion of a noble metal-bearing alloy-oxide composite. Corros. Sci. 124, 10-24 (2017).

48. Hill, D. Diffusion coefficients of nitrate, chloride, sulphate and water in cracked and uncracked chalk. J. Soil Sci. 35, 27-33 (1984).

49. Hilca, B. R. \& Triyono The effect of inhibitor sodium nitrate on pitting corrosion of dissimilar material weldment joint of stainless steel AISI 304 and mild steel SS 400. AIP Conf. Proc. 1717, 040009 (2016).

50. Kalkar, C. D. \& Doshi, S. V. Effect of nitrate ions on the oxidation of iodide ions during the dissolution of $\mathrm{Y}$-irradiated $\mathrm{NaCl}$ in aqueous binary mixture of iodide and nitrate. J. Radioanal. Nucl. Chem. 127, 161-167 (1988).

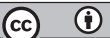

Open Access This article is licensed under a Creative Commons Attribution 4.0 International License, which permits use, sharing adaptation, distribution and reproduction in any medium or format, as long as you give appropriate credit to the original author(s) and the source, provide a link to the Creative Commons license, and indicate if changes were made. The images or other third party material in this article are included in the article's Creative Commons license, unless indicated otherwise in a credit line to the material. If material is not included in the article's Creative Commons license and your intended use is not permitted by statutory regulation or exceeds the permitted use, you will need to obtain permission directly from the copyright holder. To view a copy of this license, visit http://creativecommons. org/licenses/by/4.0/.

(c) The Author(s) 2018 